\title{
PENGARUH GAYA HIDUP, KONSEP DIRI, KELAS SOSIAL DAN HARGA TERHADAP KEPUTUSAN KONSUMEN BERKUNJUNG KE KEDAI KOPI
}

(Studi Kasus Pada Kedai Kopi XYZ di Samarinda)

\author{
Silvana Kardinar Wijayanti ${ }^{1 *}$, Widya Hana Fahleti $^{2)}$, Johan Arinato ${ }^{3)}$ \\ Sekolah Tinggi Ilmu Ekonomi Tenggarong \\ Jalan Wolter Monginsidi No. 25, Tenggarong, Kaltim \\ silvana.dinar@gmail.com
}

\begin{abstract}
Coffee has been becoming a popular commodity in Indonesia. The shift of people's lifestyles and preferences have been creating new trend in business. Coffee shops are now almost everywhere in urban areas. Marketers need to study variables affecting customer purchase/visit decision to coffee shop so they can come up with maketing programs suit to target market. The purpose of this study is to determine the effect of lifestyle, self concept, social class and price simultanously and partially on customer visit decision to coffee shop. Data collected with self-administered questionnaire distributed to 73 customers of a coffee shop in Samarinda City. Sample was collected using accidental sampling technique. Multiple linear regression in SPSS Version 22 used to analyze the data and it is revealed that social class and self concept positively and significantly affect customer purchase/visit decision. On the other hand, price found negatively and significantly affect customer purchase/visit decision to coffee shop XYZ. Whie lifestyle negatively but insignificanty affects purchase/visit decision. The results of this study suggest marketeres to use different marketing programs to different target markets.
\end{abstract}

Keywords: lifestyle, self concept, social class, price, customer visit decision.

\section{PENDAHULUAN}

Kopi telah menjadi komoditas primadona di Indonesia dalam beberapa tahun terakhir sebagai akibat dari pergeseran gaya hidup masyarakat urban yang menyukai berkumpul di kedai kopi. Menurut Solikhatun, dkk (2015) globalisasi telah mempengaruhi kebiasaan peminum kopi. Kopi yang dulunya merupakan kebiasaan orang tua dan dinikmati di warung-warung kecil di pinggir jalan, sekarang kopi justru dinikmati oleh kaula muda di kedai-kedai kopi modern.

Rezkisari (2019) menambahkan, minum kopi sudah menjadi gaya hidup bagi sebagian masyarakat Indonesia. Konsumsi kopi melonjak hingga 174 persen pada 2016, menurut data Organisasi Kopi Internasional atau International Coffee Organization (ICO). Seiring menjamurnya kedai-kedai kopi di 
perkotaan, tingkat konsumsi kopi robusta dan arabika di kalangan kaum urban terus meningkat delapan persen setiap tahunnya.

Tren ini membuat bisnis kedai kopi menjadi salah satu usaha yang paling diminati para pebisnis saat ini. Syafrudin selaku Chairman Speciality Coffee of Indonesia (SCAI) yang dikutip oleh Zuhriyah (2019) memprediksi pertumbuhan jumlah kedai kopi di Indonesia dikisaran 15-20 \%. Kondisi ini menjadi tantangan bagi para pebisnis kedai kopi yang ada untuk terus berinovasi dan mengidentifikasi variabel-variabel yang mempengaruhi perilaku konsumen dan keputusan konsumen dalam berkunjung ke kedai kopi agar usahanya mampu bertahan di tengah sengitnya persaingan di industri kedai kopi saat ini dan pada masa mendatang.

Lin, Chen dan Kuan-Shun (2010) menyarankan bahwa produsen harus mempelajari gaya hidup konsumen sasaran. Mohiuddin (2018) menyimpulkan bahwa gaya hidup merupakan faktor penting yang mempengaruhi keputusan pembelian konsumen terhadap suatu produk. Sumarwan dkk (2013) mengatakan gaya hidup (lifestyle) merupakan pola hidup yang menentukan bagaimana seseorang memilih untuk menggunakan waktu, uang, dan energi serta merefleksikan nilai-nilai, rasa, dan kesukaan.
Gaya hidup terkait dengan bagaimana seseorang hidup, bagaimana menggunakan uangnya dan bagaimana mengalokasikan waktu mereka. Perilaku yang didasari atas kebiasaan yang dilakukan, yang menjadikan hal tersebut gaya hidup di masyarakat. Sebagian masyarakat minum kopi sembari melakukan aktivitas transaksi bisnis dengan klien, atau dijadikan tempat bersilaturahmi dengan kolega atau keluarga, maupun sekedar bersantai dan berkumpul bersama teman.

Selain itu, variabel lain seperti konsep diri dan kelas sosial juga merupakan variabel yang penting menentukan kepututusan pembelian (Saputro, 2017; Durmaz dan Tasdemir, 2014). Harga juga menjadi konsep penting dalam pemasaran karena harga merupakan biaya yang langsng dapat dinilai oleh konsumen terkait kualitas produk yang dibelinya.

\section{Rumusan Masalah}

Berdasarkan penjelasan di atas, maka dirumuskan beberapa masalah penelitian sebagai berikut:

1. Apakah gaya hidup (X1), konsep diri (X2), kelas sosial (X3) dan harga (X4) berpengaruh signifikan terhadap keputusan konsumen berkunjung ke kedai kopi? 
2. Dari keempat variabel tersebut, manakah variabel yang paling berpengaruh terhadap keputusan konsumen berkunjung ke kedai kopi?

\section{Tujuan Penelitian}

Tujuan penelitian ini antara lain:

1. Untuk mengetahui pengaruh gaya hidup (X1), konsep diri (X2), kelas sosial (X3), dan harga (X4) terhadap keputusan konsumen berkunjung ke kedai kopi.

2. Untuk mengidentifikasi variabel yang paling berpengaruh terhadap keputusan konsumen berkunjung ke kedai kopi.

\section{KERANGKA TEORITIS}

\section{Keputusan Konsumen}

Fahmi (2016) mengatakan keputusan adalah proses penelusuran masalah yang berawal dari latar belakang masalah, identifikasi masalah hingga kepada terbentuknya kesimpulan atau rekomendasi. Rekomendasi itulah yang selanjutnya digunakan sebagai pedoman basis dalam pengambilan keputuasan.

Tahapan dalam pengambilan keputusan menurut Hoffman dan Bateson (2002:82), ada lima tahapan yaitu :

1. Pengenalan Kebutuhan
Proses pembelian oleh konsumen diawali sejak pembeli mengenali kebutuhan atau masalah. Kebutuhan tersebut dapat ditimbulkan oleh rangsangan internal atau eksternal.

\section{Pencarian Informasi}

Setelah konsumen yang terangsang kebutuhannya, konsumen akan terdorong untuk mencari informasi yang lebih banyak.

\section{Evaluasi Alternatif}

Evaluasi umunya mencerminkan keyakinan dan sikap yang mempengaruhi perilaku pembelian mereka. Keyakinan (believe) adalah gambaran pemikiran yang dianut seseorang tentang gambaran sesuatu.

\section{Keputusan Pembelian}

Dalam suatu kasus pembelian, konsumen bisa mengambil beberapa sub keputusan, meliputi merek, pemasok, jumlah, waktu pelaksanaan dan metode pembayaran.

\section{Gaya Hidup}

Sumarwan dkk (2013) mengatakan gaya hidup merupakan pola hidup yang menentukan bagaimana seseorang memilih untuk menggunakan waktu, uang, dan energi serta merefleksikan nilai-nilai, rasa, dan kesukaan. Gaya hidup adalah bagaimana seseorang menjalankan konsep dirinya yng 
ditentukan oleh karakteristik individu, yang terbangun dan terbentuk sejak lahir serta seiring dengan berlangsungnya interaksi sosial selang siklus kehidupan.

Konsep gaya hidup konsumen sedikit berbeda dari kepribadian. Gaya hidup terkait dengan bagaimana seseorang hidup, bagaimana menggunakan uangnya dan bagaiman mengalokasikan waktu mereka. Kepribadian menggabarkan konsumen lebih kepada perspektif internal yang memperlibatkan karakteistik pola pikir, perasaan, dan persepsi mereka terhadap sesuatu.

\section{Solamon (2011) dalam Suryani} (2013) mengatakan konsep gaya hidup dan kepribadian sering kali disamakan, padahal sebenarnya keduanya berbeda. Gaya hidup lebih menunjukkan pada bagaimana individu menjalankan kehidupannya. Gaya hidup merukan pola konsumsi yang merefleksikan pilihan individu dalam hal bagaimana mereka menghabiskan uang waktunya.

\section{Konsep Diri}

Mulyana (2000) mengatakan konsep diri adalah pandangan individu mengenai siapa diri individu, dan itu bisa diperoleh lewat informasi yang diberikan orang lain pada diri individu. Pendapat tersebut dapat diartikan bahwa konsep diri yang dimiliki individu dapat diketahui lewat informasi, pendapat, penilaian atau evaliasi dari orang lain mengenai dirinya. Individu akan mengetahui dirinya cantik, pandai, atau ramah jika ada informasi dari orang lain mengenai dirinya.

Konsep diri terdiri dari 5 komponen (Stuart \& Sundeen, 2005) yaitu :

\section{a. Gambaran diri}

Gambaran diri adalah sikap seseorang terhadap tubuhnya secara sadar atau tidak sadar termasuk persepsi dan perasaan tentang ukuran dan bentuk, fungsi penampilan dan potensi tubuh saat ini dan masa lalu.

b. Ideal diri

Ideal diri adalah persepsi individu tentang bagaimana ia harus berprilaku sesuai dengan standar pribadi. Standar ini dapat berhubungan dengan tipe orang atau sejumlah aspirasi cita-cita nilai yang di capai.

c. Harga diri

Harga diri adalah penilaian pribadi terhadap hasil yang akan dicapai dengan analisa seberapa jauh prilaku memenuhi ideal diri.

\section{d. Peran}

Peran adalah pola sikap, prilaku, nilai dan tujuan yang diharapkan dari seseorang berdasarkan posisinya di masyarakat. 
e. Identitas

Identitas adalah kesadaran akan diri yang bersumber dari observasi dan penilaian yang merupakan sintesa dari semua aspek konsep diri sebagai suatu kesatuan yang utuh.

\section{Kelas Sosial}

Suryani (2013) mendefenisikan kelas sosial sebagai pembagian angota-anggota masyarakat kedalam suatu hirarki kelas-kelas status yang berbeda, sehingga anggota dari setiap kelas yang relatif sama mempunyai kesamaan. Dengan demikian terdapat penjenjangan dalam kelas sosial, mulai dari yang paling rendah sampai denan yang paling tinggi. Dalam penegelompokan kelas sosial, status sosial sering dijadikan dasar. Status sosial adalah posisi individu dalam masyarakat, kedudukan individu dariaspek legal dan profesi seseorang. Contoh di Indonesia, masyarakat memberikan kelas sosial yangberbeda karena kedudukan yang secara legal berbeda dimasyarakat.

Menurut teori perbandingan sosial, cukup wajar bagi individu membandingkan kepemilikan materi yang dimilikinya dengan kepemilikan materi yangdipunyai orang lain denganmaksud untuk menentukan posisi relatifnya dalam hubungan sosial. Seringkali agar dapat menetapkan dalam hubungn sosial, orang perlu tahu posisinya dibandingkan dengan yang lain ditinjau dari aspek kekayaan materi yang dimiki.

\section{Sifat Kelas Sosial}

Suryani (2013) mengemukakan sifat kelas sosial berdampak pada dinamika yang terjadi di mayarakat. Terdapat dua sifat kelas sosial, yakni:

\section{Hirarkis}

Hirarkis artinya bahwa kelas sosial itu bersifat berjenjang, dari yang paling rendah, menengah, dan tinggi. Meskipun sifat hirarkis ini terjadi pada semua masyarakat, namun banyaknya jenjang bervariasi antara masyrakat yang satu dengan yang lain.

\section{Dinamis}

Kelas sosial bersifat dinamis, artinya bahwa kelas sosial seseorang konsumen dapat berubah menjadi lebih tinggi (naik), atau sebaliknya dapat mengalami penurunan. Mobilitas kelas sosial dimasyarakat sangat mungkin terjadi.Perubahan kelas sosial ini akan di ikuti dengan penyusuain pola konsumsi dan gaya hidup. Konsumen dari kelas sosial bawah yang karena kemampuan dan ketekunan meraih sukses, mendapatkan status yang tinggi dan didukung oleh kondisi 
ekonomi yang baik, akan menyesuaikan pola konsumsi dan gaya hidupnya.

\section{Harga}

Kotler dan Amstrong (2012:52) mendefinisikan harga sebagai nilai uang yang harus dibayarkan oleh konsumen untuk memperoleh suatu produk.

Menurut Kenesei dan Todd (2003), harga adalah salah satu dari beberapa biaya yang dihadapi oleh pembeli. Biaya-biaya lain termasuk biaya waktu, biaya emosional, biaya tenaga dan lain sebagainya. Namun, harga merupakan biaya yang paling mudah dinilai oleh pembeli, sehingga memegang peranan penting dalam keputusan pembelian Hurriyati (2015) menambahkan penentuan harga merupakan titik kritis dalam bauran pemasaran jasa karena harga menentukan pendapatan dari suatu usaha bisnis. Keputusan penentuan harga juga sangat signifikan di dalam penentuan nilai atau manfaat yang dapat diberikan kepada pelanggan dan memainkan peranan penting dalam gambaran kualitas jasa.

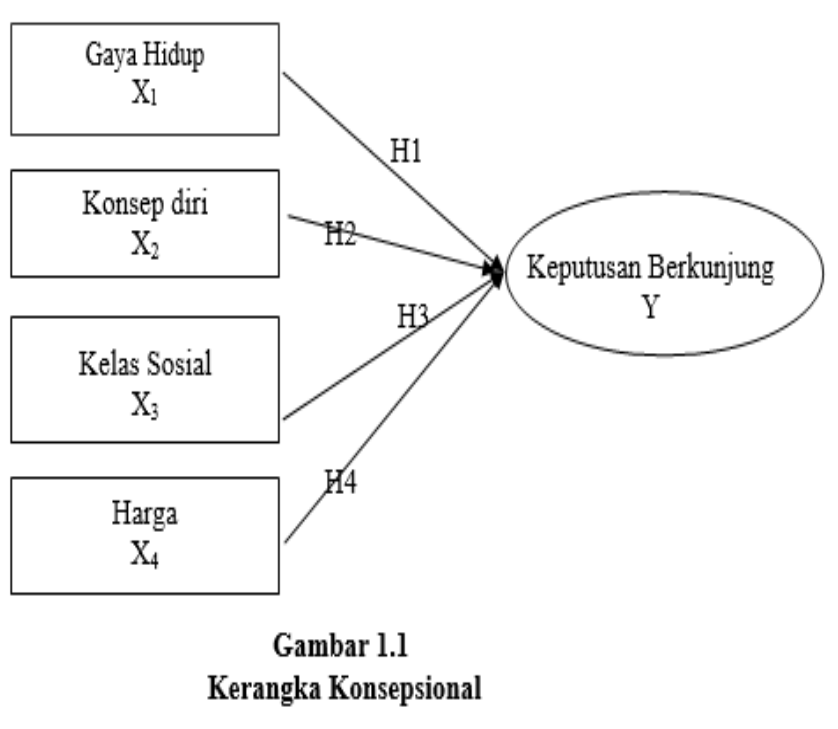

\section{Hipotesis Penelitian}

H1: Diduga gaya hidup (X1) berpengaruh signifikan terhadap keputusan berkunjung ke kedai kopi XYZ

H2: Diduga konsep diri (X2) berpengaruh signifikan terhadap keputusan berkunjung ke kedai kopi XYZ

H3: Diduga kelas sosial (X3) berpengaruh signifikan terhadap keputusan berkunjung ke kedai kopi XYZ

H4: Diduga harga (X4) berpengaruh signifikan terhadap keputusan berkunjung ke kedai kopi XYZ 


\section{METODE PENELITIAN}

\section{Rancangan Penelitian}

Pendekatan yang digunakan dalam penelitian ini adalah kuantitatif- eksplanatori (quantitative-explanatory research) karena penelitian ini ingin mencari tahu dan menjelaskan hubungan antarvariabel yaitu pengaruh gaya hidup, konsep diri, kelas sosial dan harga terhadap keputusan konsumen berkunjung ke kedai kopi.

\section{Populasi dan Sampel, serta Alat Analisis}

Berdasarkan hasil observasi awal, rata-rata konsumen yang datang ke kedai kopi XYZ di Kota Samarinda adalah 45 orang/hari. Penelitian ini dilakukan selama seminggu sehingga populasinya adalah 45 orang $\mathrm{x} 7$ hari $=315$ orang.

Dalam penentuan sampel, kami menggunakan rumus Slovin dengan tingkat kesalahan $\mathrm{e}=10 \%$ sehingga diketahui jumlah sampel adalah 73 orang. Teknik pengambilan sampel pada penelitian ini adalah accidental sampling yaitu sampel adalah siapapun yang berkunjung ke kedai kopi XYZ yang ditemui oleh peneliti dalam masa penelitian.

Seluruh data yang terkumpul dan dianggap layak kemudian dianalisis dengan regresi linear berganda pada SPSS Versi 22. Sebelumnya dilakukan uji asumsi klasik seperti uji normalitas data, uji heterokedaktisitas, dan uji multikolinearitas untuk memastikan terpenuhinya syarat Ordinary Least Square (OLS) pada model regresi.

\section{HASIL ANALISIS}

Dari 73 kuisioner yang didistribusikan, seluruhnya kembali dan layak untuk dianalisis lebih lanjut atau tingkat tanggapan pada penelitian ini adalah $100 \%$.

\section{Tabel 1: Deskripsi Profil Responden}

\begin{tabular}{clcc}
\hline Karakteristik & Jawaban & Jumlah & $\mathbf{( \% )}$ \\
\hline $\begin{array}{c}\text { Jenis } \\
\text { Kelamin }\end{array}$ & Laki-Laki & 48 & 65,8 \\
\cline { 2 - 4 } Pekerjaan & Perempuan & 25 & 34,2 \\
\hline & $\begin{array}{l}\text { Pelajar/Ma } \\
\text { hasiswa }\end{array}$ & 39 & 53,4 \\
& Karyawan & 24 & 32,9 \\
\cline { 2 - 4 } & Wirausaha & 9 & 12,3 \\
\cline { 2 - 4 } & PNS & 0 & 0 \\
\cline { 2 - 4 } Umur & Lain-lain & 1 & 1,4 \\
\cline { 2 - 4 } & $\begin{array}{l}<20 \text { tahun } \\
\text { tahun }\end{array}$ & 26 & 35,6 \\
\cline { 2 - 4 } & $\begin{array}{l}26-30 \\
\text { tahun }\end{array}$ & 13 & 46,6 \\
\cline { 2 - 4 } & $\begin{array}{l}31-35 \\
\text { tahun }\end{array}$ & 0 & 0 \\
\hline
\end{tabular}

Sumber : Output SPSS, 2019

Berdasarkan tabel 1 di atas, diketahui bahwa responden penelitian ini mayoritas adalah laki-laki sebanyak 48 orang, diikuti oleh perempuan sebanyak 25 orang. Ditilik dari segi pekerjaan, responden didominasi oleh pelajar/mahasiswa sebanyak 39 orang, diikuti dengan karyawan 24 orang dan wirausaha sebanyak 9 orang. Hal ini sejalan dengan usia 
dimana responden diketahui mayorias berumur 20-25 tahun, diikuti dengan mereka yang berumur $>20$ tahun sebanyak 26 orang dan mereka yang berumur 26-30 tahun sebanyak 13 orang. Disimpulkan bahwa pengunjung kedai kopi XYZ adalah generasi milenial.

\section{Hasil Analisis Regresi Berganda}

Tabel 2: Model Persamaan Regresi

\begin{tabular}{lllll}
\hline Model & B & T hitung & T tabel & Sig. \\
\hline 1 (Constant) & 10.077 & & & \\
Gaya Hidup & -.143 & -1.128 & $<1.66757$ & .263 \\
Konsep Diri & .476 & 2.724 & $>1.66757$ & .008 \\
Harga & -.269 & -1.857 & $>1.66757$ & .068 \\
Kelas Sosial & .414 & 4.183 & $>1.66757$ & .000 \\
\hline
\end{tabular}

Berdasarkan tabel 2 di atas, maka persamaan linear regresi pada penelitian ini adalah sebagai berikut : $\mathrm{Y}=10,077-0,143 \mathrm{X}_{1}+$ $0,476 \mathrm{X}_{2}+0,414 \mathrm{X}_{3}-0,269 \mathrm{X}_{4}$, yang maknanya sebagai berikut:

- Nilai konstanta 10.077 artinya jika gaya hidup, konsep diri, kelas sosial dan harga tidak mengalami perubahan maka keputusan berkunjung akan tetap dengan nilai 10,077 .

- Nilai koefisien gaya hidup $\left(\mathrm{X}_{1}\right)$ sebesar 0,143, artinya jika gaya hidup ditingkatkan satu satuan maka keputusan berkunjung akan menurun sebesar 0,143 atau $14,3 \%$.

- Nilai koefisien konsep diri $\left(\mathrm{X}_{2}\right)$ sebesar 0,476, artinya jika konsep diri ditingkatkan satu satuan maka keputusan berkunjung akan meningkat sebesar 0,476 atau $47,6 \%$.

- Nilai koefisien kelas sosial $\left(\mathrm{X}_{3}\right)$ sebesar 0,414, artinya jika kelas sosial ditingkatkan satu satuan maka keputusan berlunjung akan meningkat sebesar 0,414 atau $41,4 \%$.

- Nilai koefisien harga $\left(\mathrm{X}_{4}\right)$ sebesar 0,269, artinya jika variabel harga ditingkatkan satu satuan maka keputusan berkunjung akan menurun sebesar 0,269 atau $26,9 \%$.

\section{Koefisien Determinasi ( $\mathbf{R}^{2}$ )}

Untuk mengetahui nilai korelasi dan sumbangan persentase (adjusted $R$ square) antara variabel gaya hidup, konsep diri, kelas sosial dan harga terhadap keputusan berkunjung di kedai kopi XYZ dapat dilihat pada tabel 3 berikut ini :

\begin{tabular}{ll|l|l|l}
\hline & & & Std. \\
& & & Error of \\
& R & Adjusted & the \\
Model R & Square & R Square & Estimate \\
\hline 1 & $.738^{\mathrm{a}}$ & .544 & .532 & 1.76361 \\
\hline
\end{tabular}


Sumber : Output SPSS, 2019

Nilai adjusted $\mathrm{R}$ square sebesar 0,544 atau 54,4\% tingkat keputusan berkunjung ke kedai kopi XYZ dipengaruhi oleh gaya hidup, konsep diri, kelas sosial dan harga, sedangkan sisanya 45,6\% dipengaruhi oleh variabe lainnya yang tidak diteliti dalam penelitian ini.

\section{Uji Kelayakan Model (Uji F)}

Untuk menguji kelayakan model yang penelitian yang diajukan dalam penelitian ini, maka dilakukan uji simultan sebagai berikut:

Tabel 4: Hasil Uji F

\begin{tabular}{llll}
\hline Model & F & Sig. \\
\hline 1 & Regression & 7.203 & $.000^{\mathrm{b}}$
\end{tabular}

Sumber : Output SPSS, 2019

Berdasarkan tabel 4 di atas, diperoleh nilai $\mathrm{F}_{\text {hitung }}$ sebesar 7,203, sedangkan diketahui $\mathrm{F}_{\text {tabel }}=2,030$. Oleh karena nilai $\mathrm{F}_{\text {hitung }}>\mathrm{F}_{\text {tabel }}$ atau $(7,203>2,030)$ dengan signifikansi $0,000<0,10$ maka dapat disimpulkan bahwa gaya hidup, konsep diri, kelas sosial dan harga secara simultan berpengaruh signifikan terhadap keputusan berkunjung atau model yang diajukan dalam penelitian ini diterima kelayakannya.

\section{Pengujian Hipotesis (Uji t)}

\section{Tabel 5: Hasil Uji t}

\begin{tabular}{lcccl}
\hline Variabel & T hitung & T tabel & Sig. & Keputusan \\
\hline Gaya Hidup & -1.128 & $<1.66757$ & .263 & Hipotesis ditolak \\
Konsep Diri & 2.724 & $>1.66757$ & .008 & Hipotesis diterima \\
Kelas Sosial & 4.183 & $>1.66757$ & .000 & Hipotesis diterima \\
Harga & -1.857 & $>1.66757$ & .068 & Hipotesis diterima
\end{tabular}

Sumber : Output SPSS, 2019

Berdasarkan pengujian parsial menggunakan uji t yang dipaparkan pada tabel 5 di atas, dapat disimpulkan bahwa:

1. Gaya Hidup (X1) memiliki nilai t hitung $<\mathrm{t}$ tabel, yaitu $-1,128<1,66757(\alpha=$ $0.263>0.10)$, artinya gaya hidup memiliki pengaruh yang berlawanan arah dan tidak signifikan terhadap keputusan pembelian, sehingga hipotesis pertama (H1) ditolak.

2. Konsep Diri (X2) memiliki nilai t hitung $>$ t tabel, yaitu $2,742<1,66757(\alpha=$ $0.008<0.10)$, artinya konsep diri berpengaruh positif dan signifikan terhadap keputusan pembelian, sehingga hipotesis kedua (H2) diterima.

3. Kelas Sosial (X3) memiliki nilai t hitung $>$ t tabel, yaitu $4,183<1,66757(\alpha=$ $0.000<0.10)$, artinya kelas sosial berpengaruh positif dan signifikan 
terhadap keputusan pembelian, sehingga hipotesis ketiga (H3) diterima.

4. Harga (X4) memiliki nilai $\mathrm{t}$ hitung $>\mathrm{t}$ tabel, yaitu $-1,857>1,66757(\alpha=0.068$ $>0.10)$, artinya harga memiliki pengaruh berlawanan arah dan signifikan terhadap keputusan pembelian, sehingga hipotesis keempat (H4) diterima.

\section{PEMBAHASAN}

Berdasarkan penelitian ini diketahui bahwa gaya hidup (X1) merupakan satu-satunya variabel yang secara parsial tidak berpengaruh signifikan terhadap keputusan berkunjung ke kedai kopi XYZ di Samarinda. Hal ini tidak sejalan dengan Lin, Chen dan Kuan-Shun (2010) dan Mohiuddin (2018) yang menyatakan bahwa gaya hidup merupakan faktor penting yang mempengaruhi keputusan pembelian konsumen terhadap suatu produk.

Dengan nilai koefisien regresi yang bernilai negatif, dapat diartikan bahwa semakin seorang konsumen mencari nilai kebanggan dan reputasi, maka keputusan berkunjungnya ke kedai kopi XYZ cendrung menurun meskipun efeknya tidak signifikan. Responden yang mayoritas laki-laki dengan latar pekerjaan sebagai pelajar/mahasiswa mengunjungi kedai kopi untuk berkumpul dengan teman-teman atau mengerjakan tugas kuliah bersama, bukan untuk mencari reputasi/niai bangga.

Di sisi lain, konsep diri (X2), dan kelas sosial (X3) diketahui berpengaruh positif dan signifikan terhadap keputusan berkunjung. Kelas sosial (X3) juga munul sebagai variabel paling berpengaruh dalam kasus ini. Hal ini sesuai dengan Bereday (1977: 196) dan Abraham (2011: 3) dalam Durmaz dan Tesdemir (2014) bahwa stratifikasi sosial cenderung diterima sebagai fakta kehidupan. Setiap masyarakat mengelompokkan anggotanya ke dalam kelas sosial sesuai dengan nilai-nilai mereka kepada masyarakat. Para anggota kelas sosial berbagi nilai-nilai umum dan cara berpikir, berbicara, dan berperilaku yang serupa. Dengan demikian, sebagian besar konsumen berinteraksi dengan orang-orang dari kelas sosial mereka sendiri sehingga setiap kelas memiliki nilai dan pola perilaku yang sama.

Berdasarkan temuan penelitian ini, harga (X4) berpengaruh negatif dan signifikan terhadap keputusan berkunjung. Artinya, jika kedai XYZ menetapkan harga yang secara komparatif lebih tinggi daripada kedai kopi di kelasnya, maka keputusan konsumen untuk berkunjung akan menurun. Hal ini dapat dipahami karena mayoritas pengunjung merupakan pelajar/mahasiswa yang cendrung 
datang ke kedai kopi untuk sekedar nongkrong dan berkumpul bersama temanteman sebayanya, dan secara finasial pelajar/mahasiswa sebagian besar masih bergantung dengan orang tua, sehingga harga menjadi variabel penentu yang signifikan. Hasil temuan ini sejalan dengan Kenesei dan Todd (2003) bahwa harga biaya yang paling mudah dinilai oleh pembeli, sehingga memegang peranan penting dalam keptusan pembelian.

\section{KESIMPULAN}

Berdasarkan hasil penelitian dapat disimpulkan bahwa:

1. Konsep diri dan kelas sosial berpengaruh positif dan signifikan terhadap keputusan konsumen berkunjungn ke kedai kopi XY di Samarinda. Selain itu, kelas sosial muncul sebagai variabel yang paling berpengaruh dalam kasus ini.

2. Harga berpengaruh negatif dan signifikan terhadap keputusan konsumen berkunjungn ke kedai kopi XYZ di Samarinda

3. Gaya hidup berpengaruh negatif dan tidak signifikan terhadap keputusan konsumen berkunjungn ke kedai kopi XYZ di Samarinda.

\section{SARAN}

1. Kedai kopi harus dengan jelas membedakan usahanya berdasarkan kelas sosial, gaya hidup dan konsep diri pasar sasarannya sehingga program pemasaran yang diciptakan sesuai untuk pasar sasaran tersebut, mulai dari produk yang ditawarkan, penataan layout kedai, dan penetapan harganya agar menarik konsumen sasaran yang tepat.

2. Peneliti mendatang disarankan untuk menambah variabel lain yang belum diteliti dalam penelitian ini seperti eWOM, inovasi, dan kualitas produk.

3. Peneliti mendatang bisa memperbesar jumlah sampel sehingga semakin mewakili populasi atau mengganti objek penelitian ke tempat lain dengan kelompok konsumen dari kelas affluent dan sebagainya.

\section{DAFTAR PUSTAKA}

Durmaz, Y, Tasdemir, A. 2014. A Theoretical Approach to the Influence of Social Class on Consumer Behavior. American International Journal of Social Science, 3 (3), pp. 187-191.

Fahmi, Irham. (2016). Manajemen Sumber Daya Manusia. Yogyakarta : Alfabeta.

Hoffman, K. D. dan Bateson, John E.G. 2002. Essentials of Services 
Marketing: Concepts Strategies, \& Cases, 2nd ed. Texas: Harcourt College Publishers.

Hurriyati, Ratih. (2015). Bauran Pemasaran dan Loyalitas Konsumen. Bandung : Alfabetha

Kenesei, Zsofia dan Todd, Sarah. 2003. The Use of Price in The Purchase Decision. Journal of Empirical Generalisations in Marketing Science. pp. 1-21.

Kotler, Philip dan Amstrong, Gary. 2012. Principles of Marketing, 14th ed. London: Pearson Education Limited.

Lin, R. J., Chen, R. H., \& Kuan-Shun, C. K. 2010. Customer relationship management and innovation capability: An empirical study. Industrial Management \& Data Systems, 110(1), pp. 111-133.

Mohiuddin, Z.A. 2019. Effect of Lifestyle on Consumer Decision Making: A Study of Women Consumer of Pakistan. Journal of Accounting, Business and Finance Research, 2 (1), pp. 2-15.

Rezkisari, I. 2019. Bukti Kopi Sudah Jadi Gaya Hidup
Masyarakat Indonesia, [Online], Republika.co.id, (https://gayahidup.republika.co.id/berit a/py0gka328/bukti-kopi-sudah-jadigaya-hidup-masyarakat-indonesia, diakses pada 11 November 2019)

Solikhatun, Kartoto, D.T., Demartoto, A. 2015. Perilaku Konsumsi Kopi Sebagai Budaya Masyarakat Konsumsi: Studi Fenomenologi Pada Peminum Kopi di Kedai Kopi Kota Semarang, Jurnal Analisa Sosiologi, 4(1), pp. 60-74.

Sumarwan, dkk. (2013). Riset Pemasaran dan Konsumen. Bogor Edisi II: IPB Press.

Suryani Tatik, (2013). Perilaku Konsumen di Era Internet. Yogyakarta: Graha Ilmu.

Zuhriyah, D.A., 2019. Industri Kedai Kopi Ditaksir Tumbuh 20\% Tahun Ini, [Online]. Bisnis.com, https://ekonomi.bisnis.com/read/20190 822/12/1139918/industri-kedai-kopiditaksir-tumbuh-20-tahun-ini, diakses pada 11 November 2019) 